УДК 69.003:004

DOI: $10.33764 / 2687-041 X-2021-1-79-83$

\title{
ВІМ-МОДЕЛИРОВАНИЕ КАК ТЕХНОЛОГИЯ ПОВЫШЕНИЯ КОНКУРЕНТНОСПОСОБНОСТИ СТРОИТЕЛЬНОЙ ОТРАСЛИ
}

\section{Александра Ромасовна Байорис}

Сибирский государственный университет геосистем и технологий, 630108, Россия, г. Новосибирск, ул. Плахотного, 10, обучающийся, тел. (996)382-72-63, e-mail: bayoris1999@mail.ru

\section{Максим Александрович Малиновский}

Сибирский государственный университет геосистем и технологий, 630108, Россия, г. Новосибирск, ул. Плахотного, 10, ассистент кафедры кадастра и территориального планирования, тел. (383)344-31-73, e-mail: PhotoMalina76@yandex.ru

\section{Анатолий Викторович Ериов}

Сибирский государственный университет геосистем и технологий, 630108, Россия, г. Новосибирск, ул. Плахотного, 10, кандидат технических наук, доцент кафедры кадастра и территориального планирования, тел. (961)845-44-09, e-mail: er-tos@inbox.ru

В статье описывается применение ВIM в качестве повышения конкурентоспособности в строительной отрасли. Реализация ВIM осуществляется путем программноаппаратного обеспечения, позволяющего организовывать совместную работу всех заинтересованных лиц.

Ключевые слова: ВІМ-технологии, строительная отрасль, конкуренция, жизненный цикл здания

\section{BIM-MODELING AS A TECHNOLOGY TO INCREASE THE COMPETITIVENESS OF THE CONSTRUCTION INDUSTRY}

Alexandra R. Bayoris

Siberian State University of Geosystems and Technologies, 10, Plakhotnogo St., Novosibirsk, 630108, Russia, Student, phone: (996)382-72-63, e-mail: bayoris1999@mail.ru

\section{Maxim A. Malinovsky}

Siberian State University of Geosystems and Technologies, 10, Plakhotnogo St., Novosibirsk, 630108, Russia, Assistant, Department of Cadastre and Territorial Planning, phone: (383)344-31-73, e-mail: PhotoMalina76@yandex.ru

\section{Anatoly V. Ershov}

Siberian State University of Geosystems and Technologies, 10, Plakhotnogo St., Novosibirsk, 630108, Russia, Ph. D., Associate Professor, Department of Cadastre and Territorial Planning, phone: (961)845-44-09, e-mail: er-tos@inbox.ru

The article describes the application of the BIM as a competitive advantage in the construction industry. The implementation of BIM is carried out by means of software and hardware, which allows organizing the joint work of all interested parties.

Keywords: BIM technologies, construction industry, competition, building life cycle 
В настоящее время развитие строительной отрасли идет по пути активного внедрения в ее сферу информационных технологий. Повышение конкурентоспособности строительных предприятий на рынке гражданского и промышленного стротиельства во многих странах мира связывают с внедрением ВIMтехнологий. Россия в данном вопросе не является исключением, несмотря на то, что процесс внедрения BIM в ней испытывает ряд трудностей.

Цель данного исследования заключается в том, чтобы рассмотреть ВIMмоделирование в качестве технологии повышения конкурентоспособности строительной отрасли.

Для достижения поставленной цели необходимо решить следующую задачу: рассмотреть эффекты от внедрения ВІМ-технологий в строительную отрасль.

BIM - это подход к управлению жизненным циклом здания. Управление жизненным циклом здания подразумевает связанные между собой циклы, начиная от проектирования, оценки, логистики, строительства, заканчивая сносом здания.

BIM-технологии позволяют повысить конкурентоспособность компаний на рынке труда. Значительного скачка в росте производительности первое время наблюдаться не будет, наоборот, на период адаптации и внедрения ВIМ будет присутствовать некоторый спад производительности, но зато потом будет быстрыми темпами увеличиваться рост производительности.

Оценка рисков стоимости и перехода на ВIМ представлена на рис. 1 [1].

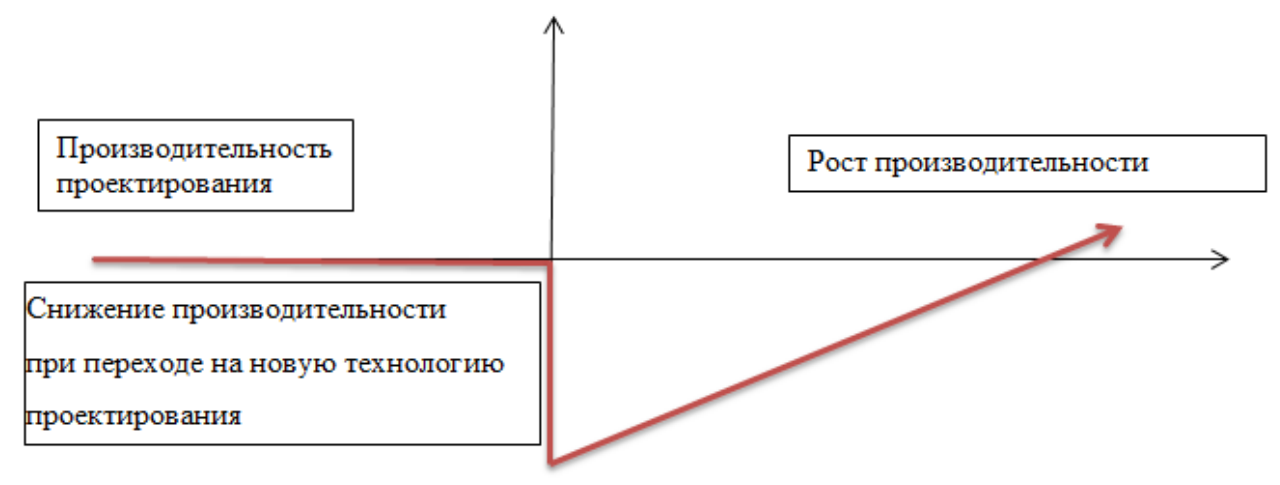

Рис. 1. Оценка рисков стоимости и перехода на ВIM

Подход к управлению жизненным циклом здания содержит три основных принципа [2]:

- совместное использование информации (участники информационного процесса совместно наполняют модель различными данными);

- «создаем один раз - используем многократно» (модель создается с помощью архитектора, конструктора, сметчика и на протяжении всего жизненного цикла может использоваться неоднократно);

- полный жизненный цикл. 
Благодаря ВIМ-моделированию можно увидеть ошибки проектировщиков, что позволяет скорректировать проектное решение в условиях уже построенного (действующего) здания.

Эффект от внедрения ВIM-моделирования приведен в таблице [3].

Переход на BIM: эффекты от внедрения

\begin{tabular}{|l|l|}
\hline Сокращение количества ошибок & $>30 \%$ \\
\hline Обнаружение пространственных коллизий & до $100 \%$ \\
\hline Ускорение процесса проектирования & $20-30 \%$ \\
\hline Сокращение времени на подготовку рабочей документации & до 3 раз \\
\hline
\end{tabular}

ВIM-моделирование облегчает и оптимизирует деятельность в строительной отрасли, позволяет, в короткий срок получить информацию о состоянии объекта с точки зрения динамики выполняемых работ по видам, объемам и с привязкой к календарным срокам.

Соответственно, данная информация, позволяет быстро реагировать на какие-либо возможные отклонения требований проекта или связанные с изменениями сметной стоимости и другими условиями договора подряда. Чем более детализирована информация о проекте, тем больше детализируется стоимость.

Для тех помещений, где происходит условно быстрая смена арендаторов, конфигурация месторасположения рабочих мест, изменений каких-либо локаций внутри офиса модель очень удобна, потому что она позволяет в очень короткие сроки смоделировать или спроектировать изменения. А если, это еще связанно с одновременным пониманием того какие материалы и какова их стоимость будет использоваться за какой-то определенный срок времени, мы, получаем модель, которая помогает снизить процент ошибок при проведении работ.

Внедрение использования ВIM-технологий повышает качество конечного продукта (проекта) для заказчика, поскольку присутствуют возможности для увеличения внимания и погружения в контрольные процедуры при отслеживании технологии выполнения строительных работ.

В качестве BIM-модели приведем проект, созданный в программном комплексе Autodesk Revit, представленный на рисунке 2.

Revit - программный комплекс реализующий принцип информационного моделирования, предназначенный для архитекторов, проектировщиков несущих конструкций и инженерных сетей.

Данная программа предоставляет возможность трехмерного моделирования элементов зданий и плоского черчения элементов в оформлении, создании пользовательских объектов организации совместной работы, над проектом начиная от концепции и заканчивая выпуском рабочих чертежей и спецификаций [4]. 


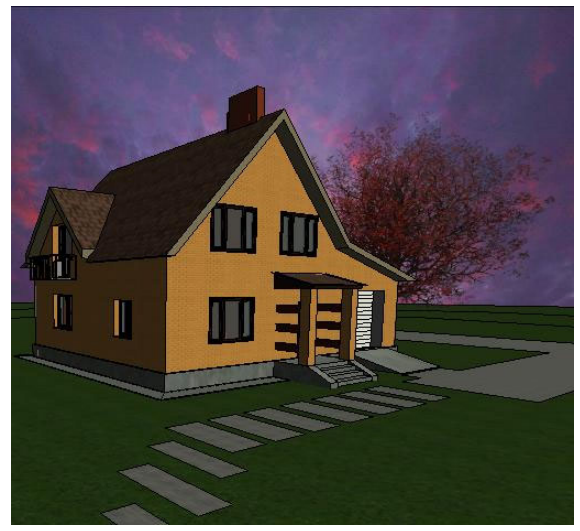

a)

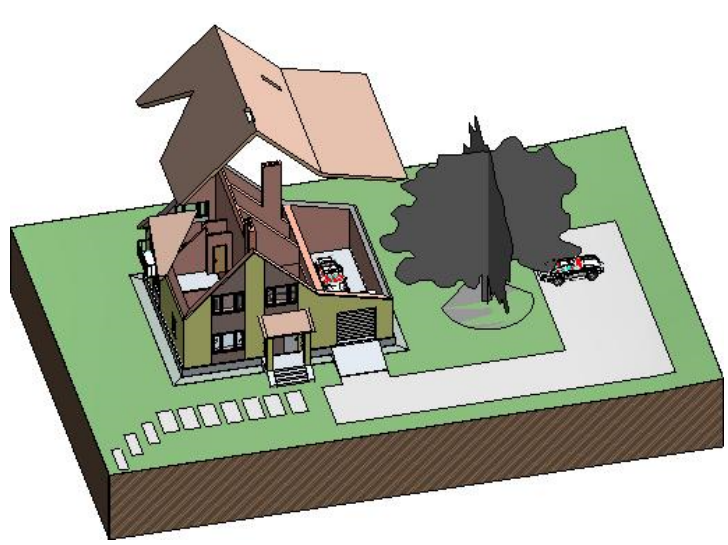

б)

Рис. 2. ВІМ-модель здания: $a$ ) реалистичный визуальный стиль; б) тонированный визуальный стиль

Эффект от внедрения ВIM-технологий получается с помощью [5]:

- автоматизации и ускорения процессов. Создавая модель один раз, мы, получаем чертежи, спецификации, взаимодействие с расчетными комплексами, армирование и другое, с помощью автоматизации;

- встроенного соответствия требованиям системы проектной документации для строительства;

- коллективной работы;

- свободы от экземплярных справочников;

- простого обмена данными через общие форматы;

- визуализации, VR.

Для того чтобы перейти на BIM-технологии необходимо уметь и знать:

- цель управления;

- совместную работу + среду общих данных;

- внедрение элементов управления. Задача управления заключается в получении проекта высокого качества.

Далее внедряются элементы управления:

- техническое задание (до создания модели, необходимо расписать, какая необходима степень детализации и что именно, отразить в данной модели);

- план выполнения проекта;

- ресурсы (участники, шаблоны);

- управление процессами (необходимо прописать деятельность работников, участвующих в проекте);

- управление качеством (проверки);

- управление изменениями.

Таким образом, ВІМ-моделирование играет важную роль в строительной сфере, так как оно увеличивает скорость выполнения и качество проек- 
тов. Дополнительным преимуществом является быстрое обнаружение коллизий в проекте, что повышает конкурентоспособность организаций в строительной отрасли.

\section{БИБЛИОГРАФИЧЕСКИЙ СПИСОК}

1. Буравлева А.Ф., Клипина Н.А., Крутилова М.О. Внедрение ВІМ-технологий в процесс проектирования и строительства объектов недвижимости // Вестник научных конференций. - 2016. - № 10-3(14). - С. 36-39.

2. Волков А.А. Информационные системы и технологии в строительстве. / учебное пособие. - М.: Московский государственный строительный университет, 2015. - 424 с.

3. Отчет по исследованию «Уровень применения ВIM в России 2019» [Электронный pecypc]. - Режим доступа: http://concurator.ru/information/bim_report_2019/.

4. AUTODESK $®$ REVIT Building 8.0: Методическое пособие. - AutoDesk, 2005.

5. Преимущества BIM в одной инфографике. Минстрой России) [Электронный ресурс]. - Режим доступа: http://www.minstroyrf.ru/press/preimushchestva-bim-v-odnoyinfografike/.

(C) А. Р. Байорис, М. А. Малиновский, А. В. Ершов, 2021 